\title{
The Pattern of Neurological Disorders; Revisited Prevalence Data of a Dedicated Neurology Clinic in Sudan
}

\section{Muaz Elsayed ${ }^{*}$, Omer Aladil Abdalla Hamid², Rayan Tonga3 ${ }^{3}$, Sara Misbah Elsadig4, Mohamed Hasan Ahmed', Musaab Ahmed6, Mohamed Khalafallah Saeed ${ }^{7}$}

\author{
${ }^{1}$ Omdurman Islamic University Faculty of Medicine and Health Sciences, Khartoum, Sudan \\ ${ }^{2}$ International University of Africa, Faculty of Medicine and Health Sciences, Khartoum, Sudan \\ ${ }^{3}$ MBBS Resident in Internal Medicine Sudan Medical Specialization Board SMSB, Khartoum, Sudan \\ ${ }^{4}$ MRCP Senior Consultant Neurologist Soba University Hospital, Department of Medicine, Faculty of Medicine, \\ University of Khartoum, Khartoum, Sudan \\ ${ }^{5}$ Department of Medicine and HIV Metabolic Clinic, Milton Keynes University Hospital NHS Foundation Trust, \\ Eaglestone, Milton Keynes, Buckinghamshire, UK \\ ${ }^{6}$ College of Medicine Physiology Department Ajman University Ajman, UAE \\ ${ }^{7}$ The University of Science and Technology, Faculty of Medicine, Omdurman Teaching Hospital, Khartoum, Sudan \\ Email: ^muaz_muaz@hotmail.com,omereladil@gmail.com, Rayanali12319@yahoo.com, \\ saramisbah@hotmail.com, elziber@yahoo.com, M.omer@ajman.ac.ae,mksaeedb@gmail.com
}

How to cite this paper: Elsayed, M., Hamid, O.A.A., Tonga, R., Elsadig, S.M., Ahmed, M.H., Ahmed, M. and Saeed, M.K. (2021) The Pattern of Neurological Disorders; Revisited Prevalence Data of a Dedicated Neurology Clinic in Sudan. Case Reports in Clinical Medicine, 10, 339-358.

https://doi.org/10.4236/crcm.2021.1011043

Received: August 25, 2021

Accepted: October 29, 2021

Published: November 1, 2021

Copyright $\odot 2021$ by author(s) and Scientific Research Publishing Inc. This work is licensed under the Creative Commons Attribution International License (CC BY 4.0)

http://creativecommons.org/licenses/by/4.0/ (c) (i) Open Access

\begin{abstract}
Background: The diverse modes in geographical locations, environmental factors, genetic and racial characteristics play a complex role in determining the pattern of neurological disorders worldwide. Determining the pattern of neurological disorders enables health policymakers to plan evidently for service, training, and research priorities. Few prevalence studies in neurology were conducted in Sudan. Methods: This is a retrospective hospital-based study that reviewed the medical records of patients who attended a Dedicated Neurology Clinic (DNC) in Omdurman, the national Capital of Sudan, for 24 months, from January 2016 to January 2018. This study aimed to determine the DNC pattern of neurological disorders as a representative subset prevalence in Sudan. Neurologists conducted the medical workup for diagnosis after at least two visits. All patients have ethically consented. Results: The total number of patients was 1050 . Only 749 patients (71.3\%) fulfilled the inclusion criteria. The mean age was $46.5 \pm 1.9$, and males were $45.3 \%$. $72 \%$ were from the Capital. The presenting symptoms were headache (16.6\%), seizures (11.5\%), limbs weakness (11.2\%), and lower percentages for other neurological symptoms. The commonest diagnoses were Stroke 12.4\%, Epilepsy 9.3\%, Primary Headache 8.8\%, Movement Disorders 7.3\%, Peripheral Neuropathy 6\%, De-
\end{abstract}


mentia 4\% Neuroinfections 1.4\%, Demyelinating Disorders 2.6\%, Spinal Spondylotic Radiculopathy $2.6 \%$ and $1.7 \%$ for Cerebral Venous Thrombosis. Conclusion: The data from Sudan-DNC showed that the most common neurological disorders descendingly were Stroke, Epilepsy, Headache, Movement Disorders, Peripheral Neuropathy, Dementia, Infections, Demyelinating Disorders, Spinal Spondylotic Radiculopathy, and Cerebral Venous Thrombosis. The demyelinating disorders and peripheral neuropathy showed a higher percentage than our previous preliminary prevalence study in 2012 compared to the other conditions, which showed similar rates in that study.

\section{Keywords}

Sudan, Prevalence, Neurological Disorder, Stroke, Dedicated Clinic

\section{Introduction}

The diverse modes in geographical locations, environmental factors, genetic and racial characteristics play a complex role in determining the pattern of neurological disorders worldwide. The burden of these diseases contributes significantly to the mortality rates in Sub-Saharan Africa, as revealed in an extensive systematic review by Connor et al. [1]. Moreover, neuro-psychiatric illnesses are responsible for $37 \%$ of healthy life lost due to adult disability in low-income countries [2]. Mortality due to neurological disorders was estimated at around $12 \%$ [2] [3], where aging represents a challenge to all health structures, including Africa [4].

The number of epidemiological studies in the third world is limited due to the cost of transportation and logistics in these countries. In low-income countries, patients with neurological disorders suffer from low diagnosis and treatment rates due to many factors [5]. Nevertheless, data produced from such research will help local health authorities to plan and the international bodies to fund priorities [6]. Furthermore, it can add answers to clinical questions, promote neurology training, and enhance specialized research. Medical records review was adopted to investigate different disciplines previously [7] and proved its usefulness and impact to define the clinical characteristics of some diseases [8] [9].

The UK Third National Morbidity Survey reported the commonest presentations, which ended in referral to the neurology service. These were ordered as headache, dizziness, spine symptoms, fits, and stroke symptoms [10]. Consultations for headache and epilepsy together may constitute $25 \%$ of the neurologist workload, as stated in a multi-center study in the UK [11], giving these disorders more influence on the daily work. The neurological disorders were estimated as $19 \%$ of the hospitalized cases in a district general hospital in Ireland [12]. On a population-based scale, $3.6 \%$ were predicted to need neurological care at one point during their life [13]. A multi-center study enrolled 18,021 patients from 
rural health centers, urban outpatient departments (OPDs), and a district general hospital emergency room showed that $12.3 \%$ of patients had neurological symptoms/diagnoses. Given the burden mentioned above of neurological disorders, efforts to study the pattern of specific neurological diagnoses were addressed in many studies globally. These studies had used various criteria, designs and were targeting different populations and locations. Few had used the international classification of diseases ICD-10, which was adopted in the 1990s.

In a study by Callixte et al., to determine the pattern of neurological disorders in Sub-Saharan Africa, the mean age was $68 \pm 7$, and $49.2 \%$ were males. Patients living in the same town were $70 \%$ of the sample size, and $3.7 \%$ were from outside Cameroon [14]. A university hospital study in Nigeria enrolled 1748 patient records; the mean age was 52.6 years. The five commonest neurological disorders were stroke $61.6 \%$, meningitis and encephalitis $13.4 \%$, tetanus $6.5 \%$, spinal cord diseases $6.5 \%$ and epilepsy $3.8 \%$. The same study reported $0.8 \%$ dementia, $0.5 \%$ myopathies and $0.3 \%$ cerebellar lesions [15].

Another study in Tanzania reported a high percentage of tremors of about $48.2 \%$, headache $41.8 \%$, strikingly stroke was $23 \%$, peripheral neuropathy $18.6 \%$, upper limb mononeuropathy 6.5\%, and Parkinson's disease as 5.9\% [16].

This Dedicated Neurology Clinic (DNC) characteristics foster the results of this epidemiological study as a prototype representing a neurology service. There are known limitations of hospital-based studies in developed countries such as Sudan. On the other hand, not all the population has access to health facilities, and they tend to attend tertiary hospitals for all levels of health. Therefore, the main objective of this research was to determine the pattern of neurological disorders in a group of patients attending a DNC.

\section{Methodology}

This is a descriptive retrospective hospital-based study. The study involved a review of the medical records of 1050 patients who attended a Dedicated Neurology Clinic (DNC). This DNC is in Omdurman town, where it receives patients from all of the states of Sudan; hence, it is called the National Capital. The town population is estimated to be three million, while Sudan's population is around 42 million [17]. The study duration was 24 months from January 2016-January 2018. The research team was composed of neurologists, a dedicated general practitioner, and a trained secretary for administrative control. In order to allocate the major outcome of this review, the main research question was: does the pattern of the confirmed diagnoses of neurological disorders in this Sudanese neurology practice match the regional and international rates?

\subsection{Inclusion Criteria}

The study included all the patients diagnosed by neurology consultants after a minimum of two clinic visits to DNC. Only 749 patients $(71.3 \%)$ satisfied the inclusion criteria. 


\subsection{Exclusion Criteria}

Patients who had a single visit to DNC and patients who had two visits to DNC but did not satisfy the diagnostic criteria either for insufficient workup, assessment failure, or because they were referred for a second opinion were excluded.

\subsection{Diagnosis}

Neurology consultants diagnose each patient after a minimum of two clinic visits.

\subsection{Evaluation Tools}

All enrolled patients were assessed at least twice by a senior consultant neurologist for the same diagnosis. Tools for assessment included personal interviews, detailed medical and neurological history, professional neurological examination, judicious use of relevant investigations and imaging techniques. The history frame adopted the standard points for the medical history and focused questions regarding neurological semiology. The questionnaire was designed and validated by Cronbach's alpha of 86 . It was filled using the registered data of patients after their or guardian's consent. The neurological examination included higher functions examination, cranial nerves, neck, upper limbs, trunk, lower limbs, back, sphincters, and gait assessments. A special note on tone, power, reflexes, coordination, and sensations was documented. Moreover, we considered characteristic neurological signs for individual neurological disorders. Various options of imaging techniques were used in relation to the specific diagnosis, which included, X-Ray of the skull, spine and chest. Computed Topograpgy (CT) Brain and Magnetic Resonance Imaging (MRI), Magnetic Resonance Angiography (MRA), Magnetic Resonance venograpgy (MRV), Magnetic Resonance spectrography (MRS) for the Brain, spine or other body parts. The minimum consultation time allowed for each patient was 30 minutes, and the maximum was one hour. The clinic secured the patient's privacy and confidentiality of information.

Data were reviewed by a trained and dedicated medical officer (who successfully completed the internship training period) and the senior consultant neurologist who documented the data initially. The structured questionnaire included demographic data, chief complaint/s, relevant past medical history $(\mathrm{PMH})$, family history $(\mathrm{FH})$, social history $(\mathrm{SH})$, drug history (DH). It also included the workup and findings of the MRI, CT Scan, electroencephalography (EEG) and nerve conduction study (NCS)/electromyography (EMG). The final diagnosis was stated clearly in the medical record.

\subsection{Data Analysis}

The coding plan was discussed with the statistician, and data was entered in SPSS version 25 for analysis. After then, the results were displayed in tables and figures. 


\subsection{Ethical Clearance}

Ethical clearance was taken directly over the phone from the competent patient or the guardians of the non-competent. Few records $(n=28)$ ethical clearance was waived by the Tertiary Center Ethical Committee.

All patients had free access to their medical data through a medical report and follow-up cards. Any competent patient was counseled or the next of kin for the incompetent. They had given their verbal consent to participate in the study. Data was secured in the hospital under the confidentiality regulations of the Sudan Medical Council (SMC).

\section{Results}

\subsection{Demographic Data}

The sample size of this study was 749 patients. Males were 339 (45.3\%) while females were 410 (54.7\%).

The mean age was $46.5 \pm 1.9 \mathrm{SD}$. Patients above 60 years of age were $27.2 \%$, the age of $40-59$ years were $39.8 \%$, while under ten years of age were $2.1 \%$. Males were $45.3 \%$, and females were $54.7 \%$. Most of the patients (74.2\%) were from the three Capital towns of Sudan; Khartoum, Khartoum North, and Omdurman. The marital status showed 419 patients who were married (56\%), singles' were 165 patients (22\%), widows were 75 patients (10\%) and divorced patients were $90(12 \%)$. Concerning the educational level, 105 patients were uneducated (14\%), school education was found in 345 patients (46\%) and 299 patients had high education (40\%) (university or higher).

Out of 749 patients, 292 (39\%) were workers, 255 (34\%) were unemployed, 97 (13\%) were students, $52(7 \%)$ were teachers, 29 (3\%) were drivers, $16(2 \%)$ were health workers, soldiers were $16(2 \%)$ and other occupations were 8 (1\%).

\subsection{Clinical Presentation}

The presenting symptoms in this group of patients included headache in $16.6 \%$, seizures in $11.5 \%$, weakness in $11.2 \%$, forgetfulness in $3.3 \%$, lower limbs' pains in $11.7 \%$, gait paralysis in $2.8 \%$, tremors were found in $3.2 \%$, abnormal movements occurred in $0.7 \%$, dizziness in $1.9 \%$. In comparison, $7.1 \%$ had low back pains (Figure 1).

Of the reviewed patients, $11.2 \%$ expressed their suffering of a degree of disability due to their neurological disease. Regarding the number of visits needed to confirm the diagnosis, $56.2 \%, 27.1 \%, 8.5 \%, 4.5 \%$, and $1.5 \%$ required two, three, four, five, and Six visits, respectively. The rest of the percentages were more than six visits.

\subsection{Patterns of Neurological Diagnosis}

Regarding the diagnoses, $12.4 \%(\mathrm{n}=93)$ had stroke, among which ischemic type 
The commonest major presenting neurological complaints in the dedicated neurology clinic DNC

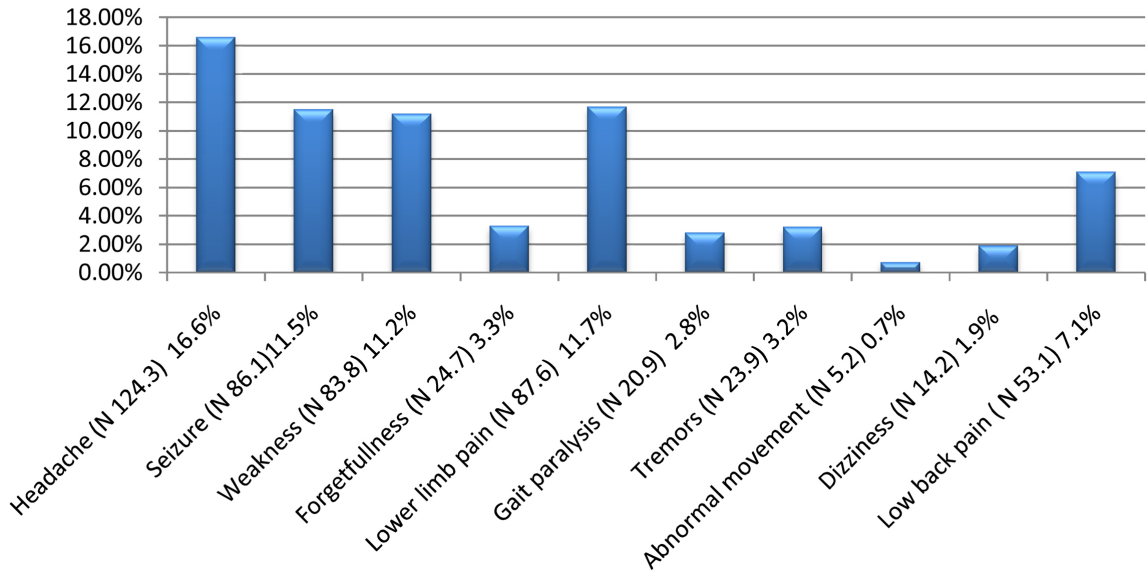

Figure 1. Illustrates the commonest presenting complaints in 749 patients attending Sudan-Dedicated neurology clinic.

was $81 \%$, other hemorrhagic stroke types were $19 \%$. Cerebral Venous Thrombosis either sinus, cortical veins or combined was found in $1.7 \%$, and retinal vein occlusion in $0.1 \%$.

Generalized epilepsy was diagnosed in $6.5 \%$, and the focal epilepsy in $0.5 \%$. Non-epileptic attacks were in $1.5 \%$, and vasovagal attacks were in $0.3 \%$. Temporal lobe sclerosis were found in $1.9 \%$ as reflected in their MRI brain with epilepsy protocol.

Lumbo-sacral root disorders mainly due to spondylotic changes were found in $14.2 \%$. Cervical radiculopathy with or without myelopathic changes was found in $6.4 \%$. The cases with cervical or dorsal myelitis due to different causes were in $0.8 \%$.

Primary Headache syndromes were diagnosed in $8.8 \%$, among which Tension-type headache was 39\%, and Migraine was $61 \%$. No Cluster headache or trigeminal Autonomic Cephalgias were encountered.

Movement disorders were found to be $7.3 \%$ of the total sample in which Idiopathic Parkinson's disease was 5.7\%. In comparison, Parkinson's Plus syndromes were $0.2 \%$, among which Multiple System Atrophy (MSA) was found in $0.1 \%$ as well as progressive Supra Nuclear Palsy (PSP). Wilson's disease $0.2 \%$, Essential Tremors was found in $0.2 \%$, stiff person syndrome $0.2 \%$, dystonia $0.4 \%$ and chorea $0.1 \%$. The idiopathic Parkinson's disease was $78 \%$ of the movement disorder representing the commonest category.

Alzheimer's disease (AD) was present in 2.1\%, vascular dementia VD in $1.9 \%$, Fronto-Temporal Lobe Dementia (FTLD) in $0.2 \%$, Diseases associated Dementia was $0.3 \%$ for each Wernicke's encephalopathy and Wilson's disease in $1.1 \%$.

Idiopathic Bell's Palsy was found in $1.2 \%$, while trigeminal neuralgia (TN) was present in $1.1 \%, 0.2 \%$ for each Oculomotor third nerve, and Abducens 6th nerve palsy. Ischemic optic neuropathy was found in $0.1 \%$. Peripheral neuropathy was found in $3.5 \%(n=26)$, where Distal diabetic sensory peripheral neuropathy 
(DDSPN) was found in 1.7\%. Carpal Tunnel Syndrome was in 2.3\%, while Axonal Sensory Motor Neuropathy in chronic inflammatory demyelinating polyneuropathy (CIDP ) was found in $0.7 \%$. Herpes zoster and postherpetic neuralgia in $0.1 \%$. Myasthenia Gravis (MG) was found in $0.5 \%$. Other cerebellar syndromes were found in $0.4 \%$. All types of hereditary ataxia with or without family history were found in $0.5 \%$ and the same for muscular dystrophy, which was $0.3 \%$. Ataxia telangiectasia (AT) was found in $0.1 \%$. Possible Multiple Sclerosis (MS) in $1.2 \%$, monophasic transverse myelitis in $0.3 \%$, and Neuromyelitis Optica Spectrum Disorders (NMOSD) in $0.1 \%$. Vertigo and other vestibular disorders constituted $1.5 \%$.

Space occupying lesions were found in 3.9\%, being either primary, secondary neoplasms, or granulomas and abscesses. The spinal metastasis was found in $0.1 \%$. Central nervous system infections, including meningitis, encephalitis, empyema, and Pott's disease, were found in $1.4 \%$, while Pott's disease alone was $0.5 \%$. Leprosy was present in $0.1 \%$.

The idiopathic intracranial hypertension (IIH) was detected in $0.9 \%$. Normal-pressure hydrocephalus (NPH) represented $0.1 \%$ and Benign Hereditary Chorea $(\mathrm{BHC})$ in $0.1 \%$. Sleep paralysis was found in $0.3 \%$ and Paget's disease of bone was found in $0.1 \%$.

Systemic lupus erythematosus (SLE) and Rheumatoid Arthritis (RA) were found in $0.5 \%$. Polymyalgia Rheumatica was in $0.1 \%$, and Temporal arteritis (GCA) in $0.1 \%$. All types of muscle spasms were $0.8 \%$. The post-traumatic disorders were $1.5 \%$.

Anxiety disorder was found in $1.5 \%$, while conversion syndrome presenting with different neurological presentations was $1.1 \%$. Hyperactivity attention deficit disorder HAAD was found in $0.1 \%$. Cerebral palsy was found in Stiff person syndrome was found in $0.3 \%$. Non-neurological disorders constituted $3.6 \%$.

\section{Discussion}

The mean age in this study was relevant to the mean age in other studies but in a lower fashion as some listed studies targeted only the elderly population. In our report, the elderly patients, i.e., 60 years and above, were $27 \%$, while patients between 40 - 60 years were $12 \%$. It reflects the accumulation of morbidity in old age and common neurological clusterings like stroke and spine disorders in the elderly. This conforming to the concept reflected in 2009 by Asekomeh et al. and stating that more trials are needed to address neurology in the elderly population, even in Africa [17]. The percentage of pediatric patients was low because the study area was an adult neurology clinic. However, access to specialized services and pediatric neurologists in the underdeveloped world is a great challenge.

A small percentage of $0.7 \%$ was from outside the country, which echoes the health status in this part of the world, the rarity of specialized consultations, and common health structures and dares. A higher percentage of 3.7\% was reported in Cameroon by Callixte et al. If we scale it on a higher level, West Africa has 
fewer regional conflicts than East Africa, which may have affected the easiness of transportation across countries.

\subsection{Stroke and 0ther Cerebrovascular Diseases}

In our study, stroke was $12.4 \%$ which is relatively consistent with the study of Komolafe et al., which reported $11.8 \%$ of stroke in adults in a University Hospital in Nigeria. The study used the ICD 10, and diagnoses were made by the neurologist [18]. However, our figure was higher than the descriptive OPD study of Callixte et al. [14] in Cameroon, which enrolled 912 patients and reported stroke in only $7 \%$. This pattern is less likely to be related to sample size differences but may indicate different risk factors for stroke or discrepancies in the more rural catchment area. As we know, rural areas tend to have more healthy lifestyles, organic food, and less pollution.

The study of neurological patterns in patients 70 years old and above by Dehurst, F. in 2012 reported a higher percentage of $29 \%$ for patients receiving appropriate treatment among 349 patients. However, this may be because of the smaller sample size, selection bias, higher likelihood of stroke in old age, and co-morbidities. The same author in 2013, using the ICD-10 in a community-based prevalence study in Tanzania, reported a lower percentage of $23 \%$ for stroke.

Another study by Anand et al. in a teaching hospital in India reported stroke in $19.1 \%$. However, $27 \%$ were above 40 years, in comparison to our study, which revealed almost $40 \%$ above forty years. In Anand et al. study, 70\% were males, and it is well-known that gender is a non-modifiable risk factor for stroke and may have contributed to that study's higher percentage.

The percentage of stroke was lower than the previous percentage found by the author of this paper in a similar study to determine the pattern in $2012(12.7 \%$ versus 20.7\%) [19]. This is due to the difference in sample size, and the first study included patients from OPD and ER while the second one only enrolled OPD cases hence missing cases of acute stroke. Nevertheless, overall the stroke in this study was the commonest neurological disorder and matched the systematic review done by Connor et al. 2007 that reported the burden of stroke in a black population of Sub-Saharan Africa. Table 1 will show the differences and similarities between the two studies among different neurological patterns in the same town.

In this study, the commonest neurological diagnoses were found to be stroke (12.4\%), epilepsy (9.3\%), headache $8.8 \%$, movement disorders (7.3\%), peripheral neuropathy (6\%), and Dementia in $4 \%$ (Figure 2).

Table 2 illustrates important details of certain diseases and their subdiagnoses.

One goal of this study was to re-evaluate the pattern of neurological diseases after few years of the first research. It had adopted almost similar setting of the population with exension of the observers. It is interesting to recognize that the stroke, headache, movement disorderscerebral venous sinus thrombosis had 
Table 1. Shows the differences and similarities between the two studies among different neurological patterns in the same town.

\begin{tabular}{lccc}
\hline & Diagnosis & \% in 2018 & \% in 2012 \\
\hline 1 & Stroke & 12.4 & 20.7 \\
2 & Epilepsy and seizures & 9.3 & 16.6 \\
3 & Headache & 8.8 & 9.6 \\
4 & Movement Disorders & 7.3 & 7.7 \\
5 & Peripheral Neuropathy & 6 & 3.6 \\
6 & CNS and PNS Infections & 1.4 & 6 \\
7 & Cerebellar disorders & 1 & 4.8 \\
8 & Demyelination disorders & 2.6 & 1.8 \\
9 & CVST & 1.7 & 1.8 \\
10 & SOL & 3.8 & 1.2 \\
11 & Myasthenia Gravis & 0.4 & 2.4 \\
12 & Dementia & 4. & Not reported \\
13 & Pott's disease & 0.5 & Not reported \\
14 & Leprosy & 0.1 & Not reported \\
\hline
\end{tabular}

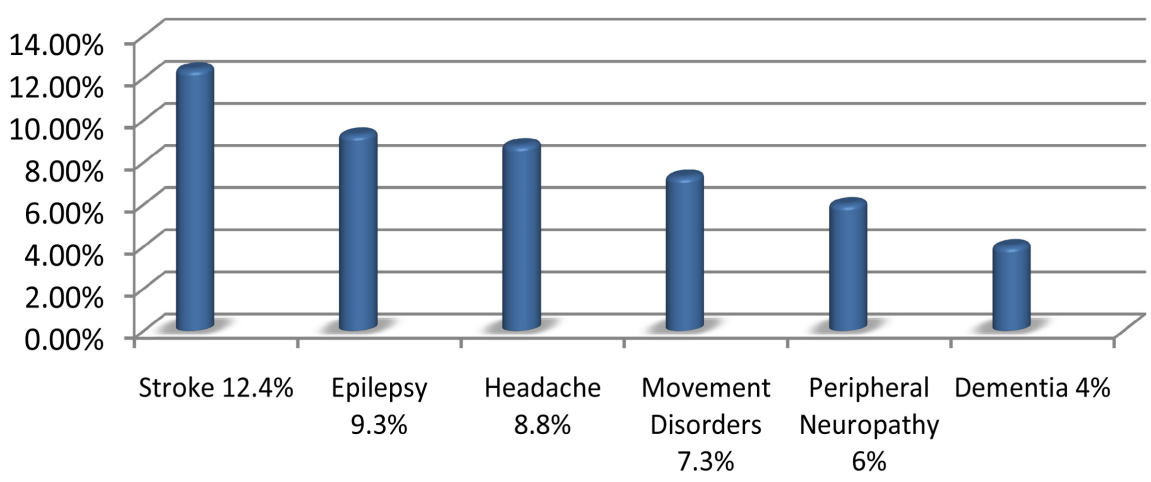

Figure 2. Showing the most encountered neurological diagnoses.

almost similar percentages which gives this study informative about the pattern of these specific diseases. However, peripheral neuropathy, space occupying lesions and demyelinating disorders were reported with higher percentages. This may be related to the recruitemht of more research members, validated questionnaire and more structured evaluation. Some disorders like cerebellar diseases may have been reported in a lower percentage because some were classified here as posterior circulation strokes rather than a primary cerebellar syndrome. On the other hand space occupying lesions (SOL) were higher than the 2012 study as tumors and granulomas were categorized as SOL in the 2018 study (Table 1).

\subsection{Epilepsy}

It is essential to recognize that neurological disorders constitute $3.6 \%$ of the need for neurology service, while hospital settings reflect a $19 \%-12.3 \%$ [12] [13]. Hence, defining the pattern of the second common neurological disorder like 
Table 2. Showing the pattern of some neurological diseases in a group of patients attending a dedicated neurology clinic in Omdurman Town Sudan (Jan 2016-Jan 2018).

\begin{tabular}{|c|c|c|c|}
\hline Neurological disorder & Number & Percentage & Notes \\
\hline Stroke & 93 & $12.4 \%$ & $\begin{array}{l}76 \text { ischemic }+17 \\
\text { hemorrhagic }\end{array}$ \\
\hline Epilepsy & 70 & $9.3 \%$ & MTLS 14 \\
\hline Headache & 66 & $8.8 \%$ & $\begin{array}{l}40 \text { Migraine }+26 \\
\text { Tension headache }\end{array}$ \\
\hline Movement disorder & 55 & $7.3 \%$ & $\begin{array}{l}43 \text { PD }+2 \text { Wilson's } \\
\text { disease }+3 \text { Dystonia }+1 \\
\text { PSP + } 1 \mathrm{MSA}+2 \text { stiff person } \\
\text { syndrome }+2 \mathrm{ET}+1 \mathrm{BHC}\end{array}$ \\
\hline Peripheral neuropathy & 45 & $6 \%$ & $\begin{array}{l}13 \text { DDPN }+17 \text { CTS }+8 \\
\text { Axonal lower limb } \\
\text { neuropathy }+5 \text { CIDP }+1 \\
\text { Leprosy }+1 \text { Herpes Zoster }\end{array}$ \\
\hline Dementia & 30 & $4 \%$ & $\begin{array}{l}16 \text { Alzheimer's Disease }+13 \\
\text { vascular dementia }+1 \text { FTLD }\end{array}$ \\
\hline Nervous system infections & 11 & $1.4 \%$ & $\begin{array}{l}4 \text { Viral encephalitis }+3 \\
\text { Brain infections }+4 \text { Pott's } \\
\text { disease of the spine }\end{array}$ \\
\hline Central Demyelination disorders & 20 & $2.6 \%$ & $\begin{array}{l}9 \text { Possible Multiple } \\
\text { sclerosis + } 1 \text { NMO Spectrum } \\
\text { disorders + } 5 \text { Cervical } \\
\text { myelitis + } 3 \text { Dorsal } \\
\text { myelitis + } 2 \text { conus } \\
\text { medullaris myelitis }\end{array}$ \\
\hline Space occupying lesions & 29 & $3.8 \%$ & $\begin{array}{l}\text { Tumors and granulomas } \\
\text { (cerebral tuberculoma } 14 \text { ) }\end{array}$ \\
\hline Cerebral venous sinus thrombosis & 13 & $1.7 \%$ & \\
\hline $\begin{array}{l}\text { Spinal Spondylosis without } \\
\text { disc disease }\end{array}$ & 73 & $9.7 \%$ & \\
\hline $\begin{array}{l}\text { Spinal spondylosis with } \\
\text { disc disease }\end{array}$ & 48 & $6.4 \%$ & \\
\hline Symptomatic spinal radiculopathy & 20 & $2.6 \%$ & \\
\hline Cranial neuropathy & 19 & $2.5 \%$ & $\begin{array}{l}8 \text { Trigeminal Neuralgia }+9 \\
\text { Bell's palsy }+1 \text { third } \\
\text { nerve }+16^{\text {th }} \text { nerve }\end{array}$ \\
\hline Other minor diagnosises & 129 & $17.2 \%$ & \\
\hline Non neurological & 28 & $3.7 \%$ & \\
\hline Total & 749 & $100 \%$ & \\
\hline
\end{tabular}

epilepsy is essential. The current study reported epilepsy and seizures to be $11.5 \%$ which is the lowest reported percentage among all studies listed here. The highest percentage was $32.9 \%$ in a university hospital in West Africa. There is no clear explanation for this from our side. Even in our previous preliminary report and despite a smaller sample size, it was found to be $16.6 \%$. Among the different 
studies listed here, it ranged from 20\% - 32\% [5] [16]. However, most of the epilepsy patients prefer to follow up in the general hospital OPDs as it is a chronic condition. The affordability issue may have played a role in this DNC concerning a common episodic disorder that may be followed up with the same neurologist in the public hospital. However, it still stands as the $2^{\text {nd }}$ commonest neurological condition after stroke, which conforms to international literature.

\subsection{Headache}

The $3^{\text {rd }}$ commonest neurological diagnosis encountered here as $8.8 \%$ as compared to a relatively similar percentage found by Callixte et al. $7.5 \%$ and $\mathrm{M} \mathrm{El-}$ sayed et al. 2012 (9.6\%) [14] [19]. However, this was relatively low, with 41.8\% reported by Dewhurst, F. in 2013 [16]. Still, the latter was a community-based study and included the elderly population only who may have other causes for the headache like anemia, UTI, glaucoma, and cervicogenic headache. Komolafe et al. [18] reported a lower figure of 6.7\%. Moreover, endemic diseases in Africa like Malaria plays a role in headache as a common symptom.

\subsection{Movement Disorders}

Our figure of $6.2 \%$ for movement disorder, including 5.9\% for Parkinson's disease, was precisely similar to the community-based study of Dewhurst 2013, which was 5.9\% for Parkinson's disease [16]. Moreover, movement disorders were near our previous findings in a general teaching hospital, which was $7.7 \%$. On the other hand, it was not relevant to Komolafe et al. which was $11.4 \%$. The percentage ranged between $10 \%-16 \%$ in different studies reflecting population, age, or design differences [14] [18] [20].

In the Dewhurst, F. study in 2012, the percentage was as high as $21.4 \%$, yet it included all Parkinsonism scope and not only Parkinson's disease [5].

\subsection{Peripheral Neuropathy (Unspecified)}

The percentage of this disorder as $6 \%$ was higher than Anand, K. S. (3.7\%) and Elsayed, M (3.6\%) [19] [20]. However, there was a clearly higher percentage in another two studies using the ICD-10, but the two studies had a $50 \%$ difference in their report of peripheral neuropathy (Callixte et al. 2015 and Dewhurst et al. 2013 [14] [16]. The former was an OPD study, while the latter was an epidemiological community study which explains the lower percentage in hospital-based studies. Komolafe et al. [18] reported a lower rate of $2.3 \%$. The differences expressed here can be explained by the vast majority of diseases and substances that cause peripheral neuropathy with the accumulation of locally endemic diseases like leprosy, HIV, and Tuberculosis in different areas.

\subsection{Others}

It is exciting and ambiguous to find a lower percentage of infectious conditions in a sub-Saharan country in Africa. However, as the cases were only reviewed in 
a tertiary center clinic, but as expected, many cases will be presenting dramatically to the ER and would have been missed in this OPD review. Hence, this will explain the $1.4 \%$ encountered here for infectious conditions. It is higher than the $0.6 \%$ reported by Komolafe et al. [18] in a hospital-based study in Nigeria, where we also expect a higher range of infectious conditions. It is essential to mention here that Pott's disease was a typical encounter in our review besides brain tuberculomas which raises the paramount importance of clinical attention to these serious endemic diseases with high morbidity, disability, and mortality.

Dementia diagnosis depends on the clinical evaluation, imaging by MRI and neuro-psychology testing. The documented follow-up is a major tool to consolidate the final diagnosis. Dementia was reported here as $3.4 \%$, which is slightly higher than $2.6 \%$ found by Komolafe et al. while Callixte et al. reported a higher percentage of $11.2 \%$. Our review's breakdown of these percentages showed Alzheimer's disease as the commonest $(2.1 \%)$ of the total cases and $53 \%$ of dementia cases. The frontotemporal lobe dementia FTLD being ten times less $(0.2 \%)$, while vascular Dementia came second with $1.9 \%$. This percentage order conforms to the international literature as Alzheimer's disease is the commonest followed by Vascular Dementia and then the rest of the subtypes [21] [22].

Demyelinating disorders, including possible multiple sclerosis and other transverse myelitis, were reported as $1.6 \%$, which conforms to what has been found previously in 2012 as $1.8 \%$. Nevertheless, regarding their severe disability, they must be encountered as an important category in Africa's neurological disorders.

Interestingly, the percentage of cerebral venous sinus thrombosis and cortical thrombosis is almost static in 2012 and 2018, being $1.7 \%$ and $1.8 \%$, respectively. Therefore, the consensus and experts' opinion in the neuroscience society in Sudan SSNS is "this condition is emerging as a serious potentially treatable condition with major disability and mortality in the young population and pregnant women which deserves more research and health awareness in certain target groups".

Tumors reported here were higher than in the 2012 study (3.9\% versus $1.2 \%$ ) [19]; however, all space-occupying lesions were included in this study. This may have added some granulomatous and abscesses to the percentage.

\section{Limitations}

The limitations here include a single clinic view and a single professional assessor. There were no follow-up details for specific neurological disorders. The lack of advanced testing like genetic and special immune tests in few diagnoses may have cornered the diagnostic plasticity. The location of the study in the Capital may not reflect the nationwide pattern. Finally, the application of ICD 10 was not performed.

\section{Conclusion}

This is a neuro-epidemiological hospital-based study; where Stroke syndromes 
were the most common neurological disorders. Then epilepsy, headache, movement disorders, and peripheral neuropathy, Dementia mostly conforming to the international and regional data. Similarities between the paper of 2012 and this paper in some disorders may reflect a near percentage of the actual pattern in Sudan, especially demyelinating disorders, peripheral neuropathy, and cerebral venous thrombosis. MRI scans are more likely yielding in neurological disorders than CT scans. Further epidemiological/multi-center studies will help determine the natural pattern of neurological disorders in Sudan.

\section{Acknowledgements}

We thank inputs from our other colleagues who helped to edit this paper.

\section{Ethical Approval and Consent to Participate}

This work followed the guidelines for human studies and was conducted ethically in accordance with the World Medical Association Declaration of Helsinki. Verbal and written informed consents were obtained from patients to participate in this study.

\section{Consent for Publication}

The consent for publication was obtained from both the patients and Alia's Specialized Hospital ethical committee.

\section{Availability of Supporting Data}

The data is stored in Alia's Specialized Hospital, Khartoum Sudan, under the regulations of the Sudan Medical Council.

\section{Authors Contributions}

Dr. M E was responsible for the literature review, neurological assessment of the patient, writing of discussion, and references. Dr. Omer Aladil was responsible for designing and validating the questionnaire, verifying the demographic data, writing and editing all sections of the paper. Dr. Rayan Tonga had collected the data and help in statistical analysis. Dr. M Ahmed, Dr. Sara Elsadig, Dr. Mohamed Saeed, and Dr. Musaab Ahmed contributed to reviewing and editing the manuscript. All authors have approved the final draft of the manuscript before sending it for publication.

\section{Competing Interests}

The authors have no competing interests to declare.

\section{References}

[1] Connor, M.D., Walker, R., Modi, G. and Warlow, C.P. (2007) Burden of Stroke in Black Populations in Sub-Saharan Africa. Lancet Neurology, 6, 269-278. https://doi.org/10.1016/S1474-4422(07)70002-9 
[2] Murray, C.J., Vos, T., Lozano, R., Naghavi, M., Flaxman, A.D., Michaud, C., et al. (2012) Disability-Adjusted Life Years (DALYs) for 291 Diseases and Injuries in 21 Regions, 1990-2010: A Systematic Analysis for the Global Burden of Disease Study 2010. Lancet, 380, 2197-2223. https://doi.org/10.1016/S0140-6736(12)61689-4

[3] Azim, S., Zahoor, S., Janjua, J., Majeed, A. and Hussain, S.W. (2017) Analysis of the Pattern of Mortality in Medicine and Allied Departments at a Tertiary Care Hospital in Islamabad: A Losing Battle against Sepsis. The Journal of the Pakistan Medical Association, 67, 54-57.

[4] The Lancet Neurology (2009) Neurology in the Elderly: More Trials Urgently Needed. Lancet Neurology, 8, 969. https://doi.org/10.1016/S1474-4422(09)70265-0

[5] Dewhurst, F., Dewhurst, M.J., Gray, W.K., Chaote, P., Howlett, W., Orega, G., et al. (2012) Rates of Diagnosis and Treatment of Neurological Disorders within a Prevalent Population of Community-Dwelling Elderly People in Sub-Saharan Africa. Journal of Epidemiology and Global Health, 2, 207-214. https://doi.org/10.1016/j.jegh.2012.11.002

[6] Elsayed, M.A.M., Mohammed, M.A., Ibnouf, M., Yasin, F., Hamadelneel, N. and Alnagarabi, L. (2012) Preliminary Report on the Neurology Workload in a Central Hospital in Sudan. Sudan Journal of Medical Sciences, 7, 233-237.

[7] Page, K.R., Sifakis, F., Montes de Oca, R., Cronin, W.A., Doherty, M.C., Federline, L., et al. (2006) Improved Adherence and Less Toxicity with Rifampin vs. Isoniazid for Treatment of Latent Tuberculosis: A Retrospective Study. Archives of Internal Medicine, 166, 1863-1870. https://doi.org/10.1001/archinte.166.17.1863

[8] Zhang, T., Zhu, Q., Zhang, X., Ding, Y., Steinhoff, M., Black, S., et al. (2012) The Clinical Characteristics and Direct Medical Cost of Influenza in Hospitalized Children: A Five-Year Retrospective Study in Suzhou, China. PLoS ONE, 7, Article ID: e44391. https://doi.org/10.1371/journal.pone.0044391

[9] Zaide, G.B., Pekmezaris, R., Nouryan, C.N., Mir, T.P., Sison, C.P., Liberman, T., et al. (2013) Ethnicity, Race, and Advance Directives in an Inpatient Palliative Care Consultation Service. Palliative \& Supportive Care, 11, 5-11. https://doi.org/10.1017/S1478951512000417

[10] Hopkins, A. (1989) Lessons for Neurologists from the United Kingdom Third National Morbidity Survey. Journal of Neurology, Neurosurgery \& Psychiatry, 52, 430-433. https://doi.org/10.1136/jnnp.52.4.430

[11] Hopkins, A., Menken, M. and DeFriese, G. (1989) A Record of Patient Encounters in Neurological Practice in the United Kingdom. Journal of Neurology, Neurosurgery \& Psychiatry, 52, 436-438. https://doi.org/10.1136/jnnp.52.4.436

[12] Morrow, J.I. and Patterson, V.H. (1987) The Neurological Practice of a District General Hospital. Journal of Neurology, Neurosurgery \& Psychiatry, 50, 1397-1401. https://doi.org/10.1136/jnnp.50.11.1397

[13] Kurtzke, J.F. (1982) The Current Neurologic Burden of Illness and Injury in the United States. Neurology, 32, 1207-1214. https://doi.org/10.1212/WNL.32.11.1207

[14] Callixte, K.T., Clet, T.B., Jacques, D., Faustin, Y., Francois, D.J. and Maturin, T.T. (2015) The Pattern of Neurological Diseases in Elderly People in Outpatient Consultations in Sub-Saharan Africa. BMC Research Notes, 8, Article No. 159. https://doi.org/10.1186/s13104-015-1116-x

[15] Chapp-Jumbo, E.N. (2004) Neurologic Admissions in the Niger Delta Area of Nigeria-A Ten Year Review [Les maladies neurologiques observees en hospitalisation, sur une periode de 10 ans dans la region du delta au Nigeria]. African Journal of Neurological Sciences, 23, 14-20. 
[16] Dewhurst, F., Dewhurst, M.J., Gray, W.K., Aris, E., Orega, G., Howlett, W., et al. (2013) The Prevalence of Neurological Disorders in Older People in Tanzania. Acta neurologica Scandinavica, 127, 198-207. https://doi.org/10.1111/j.1600-0404.2012.01709.x

[17] Statista 2021 (2021) Sudan: Total Population from 2015 to 2025. https://www.statista.com/statistics/727157/total-population-of-sudan/

[18] Komolafe, M.A., Owagbemi, O.F. and Alimi, T.I. (2018) The Distribution and Pattern of Neurological Disease in a Neurology Clinic in Ile-Ife, Nigeria. Nigerian Journal of Clinical Practice, 21, 1520-1524.

[19] Elsayed, M. (2012) Preliminary Report on the Neurology Workload in a Central Hospital in Sudan. Sudan Journal of Medical Sciences, 7, 233-237.

[20] Anand, K.S., Singh, M. and Chandra, S.M. (1993) Pattern of Neurological Disorders above the Middle Aged Population in JIPMER, Pondicherry. Neurology India, 41, 157-164.

[21] Bermejo-Pareja, F., Benito-Leon, J., Vega, S., Medrano, M.J. and Roman, G.C. (2008) Neurological Disorders in Central Spain Study G. Incidence and Subtypes of Dementia in Three Elderly Populations of Central Spain. Journal of the Neurological Sciences, 264, 63-72. https://doi.org/10.1016/j.jns.2007.07.021

[22] Liu, H.C., Lin, K.N., Teng, E.L., Wang, S.J., Fuh, J.L., Guo, N.W., et al. (1995) Prevalence and Subtypes of Dementia in Taiwan: A Community Survey of 5297 Individuals. Journal of the American Geriatrics Society, 43, 144-149.

https://doi.org/10.1111/j.1532-5415.1995.tb06379.x 


\section{Annex}

The pattern of neurological disorders;

Revisited prevalence data of a Dedicated Neurology Clinic in Sudan.

\section{Questionnaire}

For the data collector, competent patient and Co-patient Next of kin

All questions contained in this questionnaire are strictly confidential and are used only for research purposes where no disclosure will point to the patient.

\begin{tabular}{|c|c|c|c|c|c|c|}
\hline \multicolumn{6}{|l|}{ Patient Name } & Phone \\
\hline \multicolumn{7}{|c|}{ Number Of visits } \\
\hline One & Two & Three & Four & Five & Six & $>6$ \\
\hline \multicolumn{7}{|c|}{ Extra Notes } \\
\hline \multicolumn{2}{|c|}{ Diagnosis } & \multicolumn{3}{|c|}{ Final } & \multicolumn{2}{|c|}{ Provisional } \\
\hline
\end{tabular}

\section{Demographic Data}

Patient name:

Sex: $\square$ M $\square$ F

Age:

Marital status: $\square$ Single $\square$ Married $\square$ Divorced $\square$ Widowed

Residency: $\square$ Khartoum $\quad \square$ Khartoum North $\quad \square$ Omdurman.

$\square$ States

Other

Preferred Phone: ( $\square$ Home $\square$ Cell $\square$ Other )

Preferred Time for call:

Chief complaint/s

\begin{tabular}{|c|l|l|}
\hline & Onset & Duration \\
\hline Disturbed Consciousness & & \\
\hline Syncope & & \\
\hline Speech difficulties & & \\
\hline Swallowing difficulties & & \\
\hline Headache & & \\
\hline Ocular defects & & \\
\hline Vertigo & & \\
\hline seizure & & \\
\hline Motor symptoms & & \\
\hline Sensory symptoms & & \\
\hline Sphincteric disturbances & & \\
\hline
\end{tabular}

\section{$\underline{\text { Review of Neurology Disorder: }}$}


Have the patient had any disorder related toNeurology? $\square$ Yes $\square$ No $\square$ Not clear

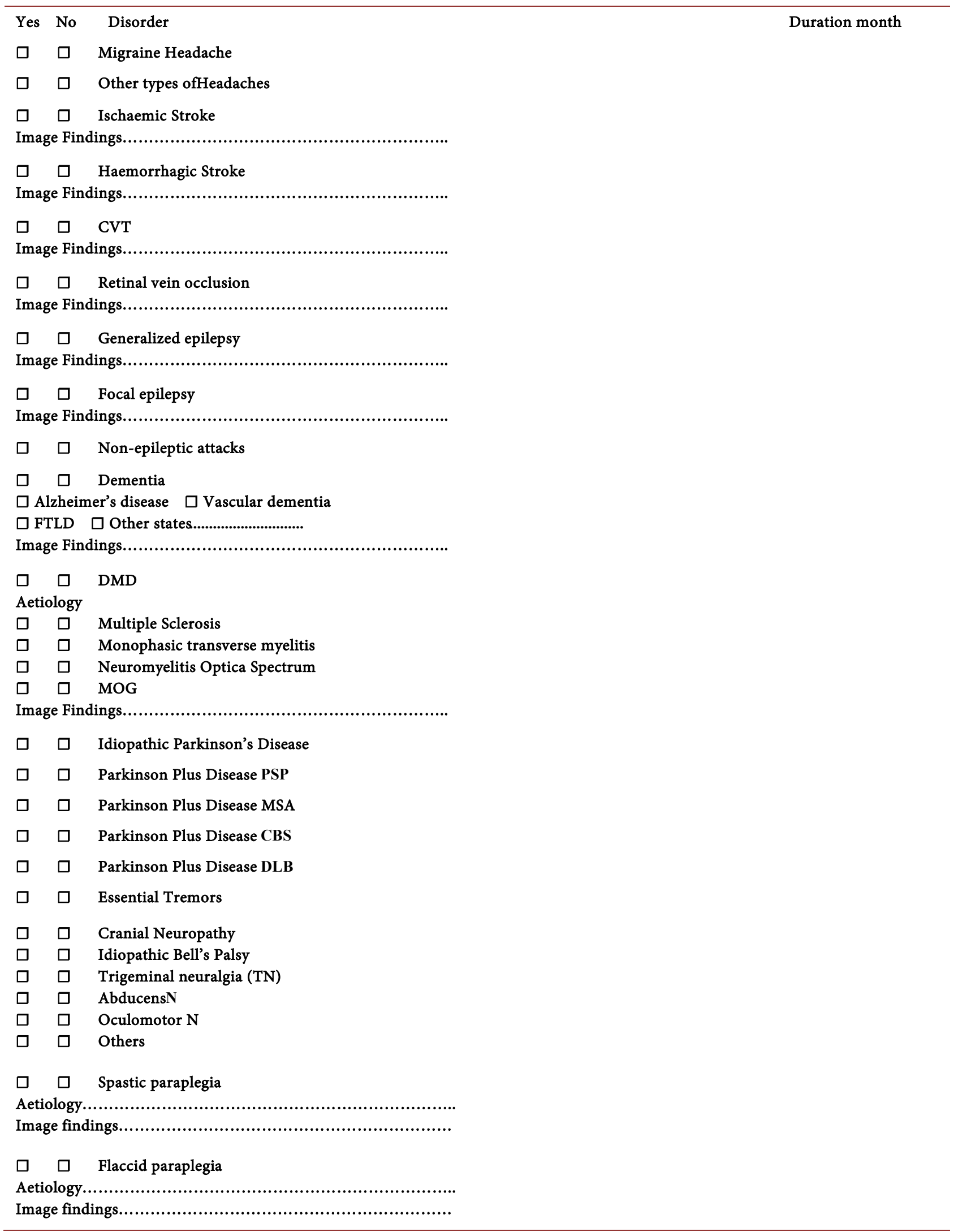




\section{Continued}

\begin{tabular}{|c|c|c|}
\hline$\square$ & $\square$ & Peripheral neuropathy \\
\hline \multicolumn{3}{|c|}{ Pattern:... } \\
\hline$\square$ & $\square$ & Distal diabetic sensory peripheral neuropathy \\
\hline$\square$ & $\square$ & Carpal Tunnel Syndrome \\
\hline$\square$ & $\square$ & Axonal Sensory Motor Neuropathy \\
\hline$\square$ & $\square$ & CIDP \\
\hline$\square$ & $\square$ & Myasthenia Gravis (MG) \\
\hline$\square$ & $\square$ & cerebellar syndromes \\
\hline
\end{tabular}

$\square \quad \square \quad$ Muscular dystrophy : Aetiology

$\square \quad \square \quad$ Vertigo and other vestibular disorders

\begin{tabular}{|c|c|c|}
\hline$\square$ & $\square$ & Space occupying lesions \\
\hline$\square$ & $\square$ & Primary \\
\hline$\square$ & $\square$ & Secondary neoplasms \\
\hline$\square$ & $\square$ & Granulomas \\
\hline$\square$ & $\square$ & Abscesses \\
\hline$\square$ & $\square$ & Spinal metastasis \\
\hline$\square$ & $\square$ & Central nervous system infections, \\
\hline$\square$ & $\square$ & Meningitis \\
\hline$\square$ & $\square$ & Encephalitis \\
\hline$\square$ & $\square$ & Empyema \\
\hline$\square$ & $\square$ & Pott's disease \\
\hline$\square$ & $\square$ & Leprosy \\
\hline$\square$ & $\square$ & Idiopathic intracranial hypertension \\
\hline$\square$ & $\square$ & NPH \\
\hline$\square$ & $\square$ & Hearing loss \\
\hline$\square$ & $\square$ & Benign Hereditary Chorea \\
\hline$\square$ & $\square$ & Sleep paralysis \\
\hline$\square$ & $\square$ & Lightheaded on standing \\
\hline$\square$ & $\square$ & Paget's disease of bone \\
\hline$\square$ & $\square$ & Systemic lupus erythematosus (SLE) \\
\hline$\square$ & $\square$ & Rheumatoid Arthritis (RA) \\
\hline$\square$ & $\square$ & Temporal arteritis (GCA) \\
\hline$\square$ & $\square$ & The post-traumatic disorders \\
\hline$\square$ & $\square$ & Conversion syndrome \\
\hline$\square$ & $\square$ & Hyperactivity attention deficit disorder HAAD \\
\hline$\square$ & $\square$ & Anxiety \\
\hline$\square$ & $\square$ & Cerebral palsy \\
\hline$\square$ & $\square$ & Stiff person syndrome \\
\hline$\square$ & $\square$ & Other \\
\hline
\end{tabular}




\section{Past Medical History}

Have the patient had any of these systemic symptoms?

Yes No Explain

Yes No

$\square \square \quad$ Hypertension

Duration:

Diabetes Mellitus

Duration:

IHD/ACS

Duration:

CKD

Duration:

Review of Systems:

\section{Fevers/sweats}

Weight gain/loss

Palpitations

Chest pain

Lightheaded on standing

Cough

Difficulty breathing

Nausea

Vomiting

Stomach pain

Urinary urgency

Urinary incontinence

Miscarriages

Neck pain

Back pain

Joint aches

Rash

Family history (please note stroke/TIA, seizure/epilepsy, migraine/headaches, dementia/Alzheimer's, Parkinson's disease, tremor, multiple sclerosis, neuropathy, muscle disease, MS, or non-neurologic disorder).

\begin{tabular}{|l|l|l|l|}
\hline & Age(s) now/at death & Medical problem(s) \\
\hline Mother & $\square Y \square N$ & & \\
\hline Father & $\square Y \square N$ & & \\
\hline Sister(s) & $\square Y \square N$ & & \\
\hline Brother(s) & $\square Y \square N$ & & \\
\hline Daughter(s) & $\square Y \square N$ & & \\
\hline Son(s) & $\square Y \square N$ & & \\
\hline
\end{tabular}

\section{Social Status}

Are you working? $\square$ Yes $\square$ No

Current or past occupation:

Highest level of education:

Smoking? $\square$ No $\square$ Yes,

Alcohol intake? $\square$ No $\square$ Yes,

current $\square$ Yes, past $\quad$ If yes, for how many years?

Illicit drugs? $\square$ No $\square$ Yes,

current $\square$ Yes, past

If yes, how many drinks per week?

Drug History 
M. Elsayed et al.

\begin{tabular}{|l|l|}
\hline Name Of the Drug & Duration \\
\hline & \\
\hline & \\
\hline & \\
\hline & \\
\hline
\end{tabular}

Workup and Findings of Investigations

\begin{tabular}{|c|c|c|}
\hline Investigation & Findings & Notes \\
\hline MRI & & \\
\hline CT Scan & & \\
\hline EEG & & \\
\hline NCS & & \\
\hline EMG & & \\
\hline CSF & & \\
\hline Other State & & \\
\hline
\end{tabular}

\section{Collector Name}

Signature

Date 